\title{
Noncompaction of Ventricular Wall - A Threat to Life
}

\author{
NILUFAR FATEMA ${ }^{1}$, AHMED SAIFUL BARI ${ }^{1}$, NAZNIN SULTANA ${ }^{1}$, MOHAMMAD AL MAMUN ${ }^{1}$, SM MUSTAFA \\ ZAMAN $^{1}$, MD. HARISUL HOQUE ${ }^{1}$, CHOUDHURY MESHKAT AHMED ${ }^{1}$, FAZLUR RAHMAN ${ }^{1}$, MD ASHRAF UDDIN \\ SULTAN $^{1}$, KHORSHED AHMED ${ }^{1}$, SAJAL KRISHNA BANERJEE ${ }^{1}$, MD. ABU SIDDIQUE ${ }^{1}$, SHEIKH MUHAMMAD \\ ABU BAKAR ${ }^{2}$ \\ ${ }^{1}$ Department of Cardiology, Bangabandhu Sheikh Mujib Medical University (BSMMU), Shahbag, Dhaka, ${ }^{2}$ Department of \\ Anatomy, Ibrahim Medical College, Shahbag, Dhaka. \\ Address of correspondence: Nilufar Fatema, Department of Cardiology, BSMMU, Shahbag, Dhaka. Email: \\ nilufar.fatema@gmail.com
}

\begin{abstract}
:
Ventricular noncompaction is a kind of cardiomyopathy which is called Noncompaction Cardiomyopathy (NCC). In this condition in which the muscular wall of the main pumping chamber of the heart -the left ventricle (LV) appears to be spongy and "non-compacted", consisting of a meshwork of numerous muscle bands called trabeculations. Here, anatomically $L V$ wall has deep trabeculations. This condition is associated major clinical problems like systolic and diastolic dysfunction, arrhythmia and even systemic embolism. Sudden cardiac death may occur in this group. Early detection of this condition may help to plan the management.
\end{abstract}

Key words: Noncompaction Cardiomyopathy, ventricular trabeculations, spongy myocardium.

\section{Introduction:}

The foetal heart muscle has a non-compacted appearance between the 4th and 18th week of development. This noncompaction is important for the nutrition of its cells. The spongy-like heart muscle is supplied predominately by diffusion of blood in the heart that flows into the spaces between the muscle bands. Later with the development of the coronary arteries, which will eventually take over carrying blood to the heart muscle, development of the muscle bands appears to go backwards. As normal development progresses, these trabeculated structures undergo significant compaction that transforms them from spongy to solid. Failure of compaction process results noncompaction cardiomyopathy (NCC).

\section{Genetics:}

A number of genes are thought to be associated with this condition. These are mainly genes that encode information important for the construction of the skeleton of the muscular cell. The identification of these genes became possible after it was noticed that a number of patients with non-compacted myocardium belonged to families where more members were affected to various extents. The American Heart Association's 2006 classification of cardiomyopathies considers NCC a genetic cardiomyopathy. ${ }^{1}$ Mutations in LDB3 (also known as "Cypher/ZASP”) have been described in patients with the condition. ${ }^{2}$ There is recent information in which NCC has been seen in combination with 1q21.1 deletion syndrome.

\section{Symptoms:}

Wide range of symptoms is found of non-compaction cardiomyopathy patients. It is possible to be diagnosed with the condition, yet not to suffer from any of the symptoms associated with heart disease. ${ }^{3}$ Likewise it possible to suffer from severe heart failure, ${ }^{4}$ which even though the condition is present from birth, may only manifest itself later in life. ${ }^{3}$ Differences in symptoms between adults and children are also prevalent with adults more likely to suffer from heart failure and children from depression of systolic function. ${ }^{3}$ Common symptoms associated with a reduced pumping performance of the heart include: 5

- breathlessness

- fatigue

- $\quad$ swelling of the lower extremities

- limited physical capacity and exercise intolerance.

Young children can present with cyanosis, syncope, dysmorphic features and failure to thrive.

\section{Risk related to this condition:}

- This condition is also thought to be associated with increased risk of blood clots in the meshwork of the prominent heart muscle bands. This is explained by the fact that the blood flow in this region of the heart is relatively slow. Most recent studies have shown that the risk of clot formation has previously been overestimated and is mainly associated with the pumping function of the heart. 
- Another risk possibly associated with this condition is that of a fast cardiac rhythm which may result in a drop in blood pressure, loss of consciousness and, if not treated, death in rare cases. These arrhythmias have also been observed in individuals with cardiac problems of other causes. So it is not certain that they are exclusively associated with non-compacted heart muscle.

\section{Investigations:}

\section{ECG:}

Biventricular hypertrophy with extreme QRS voltages, Isolated or diffuse T-wave changes and in some it is associated with WPW syndrome with premature atrial and ventricular contractions.

\section{Chest X-ray:}

Cardiomegaly and sign of pulmonary congestion may be found.

\section{Echocardiography:}

Trabeculation of the ventricles is normal, as are prominent, discrete muscular bundles greater than $2 \mathrm{~mm}$. In non compaction there is excessively prominent trabeculations. Chin, et al. described echocardiographic method to distinguish non compaction for normal trabeculation. They described a ratio of the distance from the trough and peak, of the trabeculations, to the epicardial surface. ${ }^{6}$ Non compaction is diagnosed when the trabeculations are more than twice the thickness of the underlying ventricular wall. So, diagnosis is made by echocardiography. Currently three echocardiographic creteria for diagnosis of typical Noncompaction:

1) Presence of multiple trabeculations, particularly in the apex and free wall of the left ventricle.

2) Multiple deep intertrabecular recesses communicating with the ventricular cavity, as demonstrated by color doppler imaging.

3) A 2-layered structure of endomyocardium with an increased noncompacted to compacted ratio (suggested as $>2$ in adults, $>1.4$ in children)

\section{Cardiac MRI:}

Now a day, Cardiac MRI is available in developed country. This is the most accurate method to diagnosis of noncompaction.

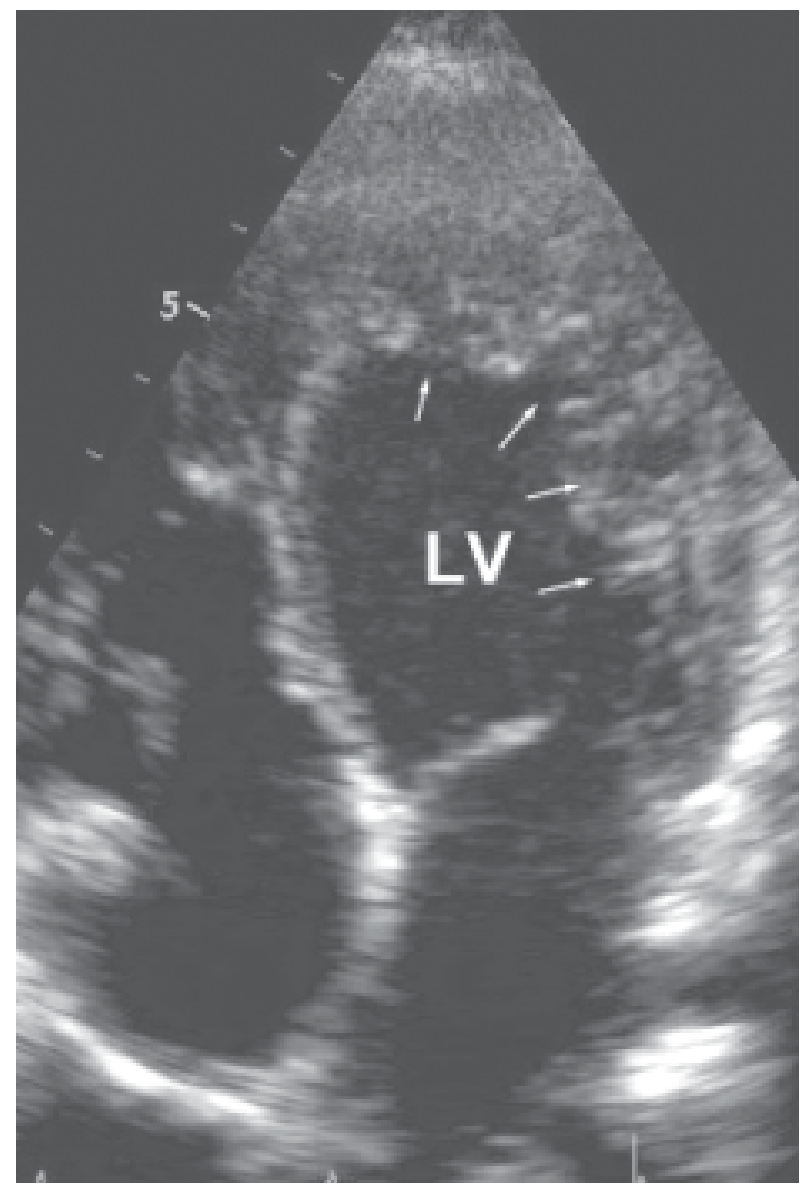

Fig.-1: Apical 4-chamber view in 2D echocardiography showing Noncompacted Myocardium in Left ventricle.

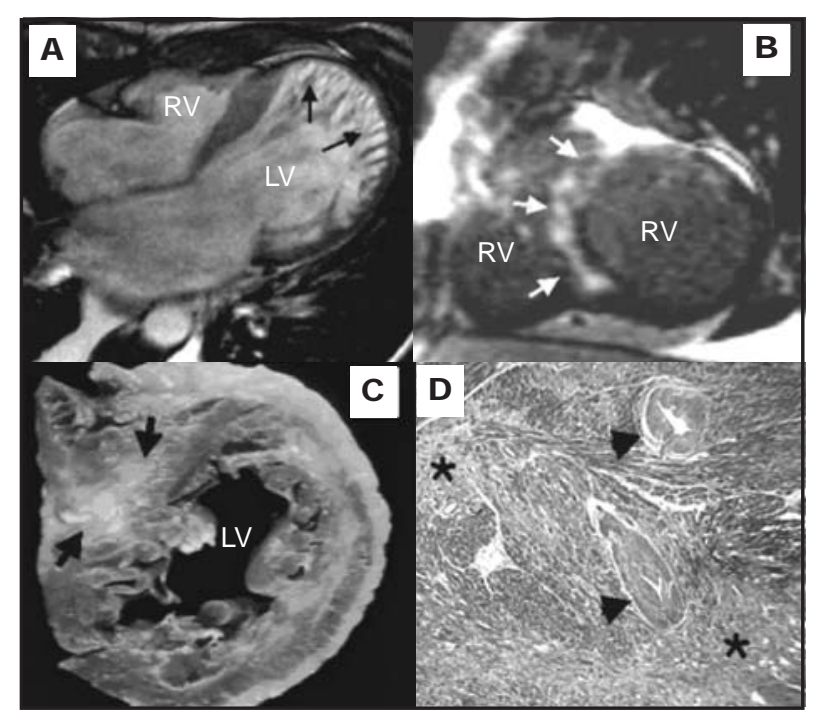

Fig.-2: Panel-A and $B$ showing hyper trabeculations in $L V$ wall in Cardiac MRI (CMR).

Panel-C showing cardiac morphology in Noncompaction and Panel-D showing histological appearance of Noncompaction cardiomyopathy. 


\section{Management:}

One paper has listed the various types of management of care that have been used for various types of noncompaction cardiomyopathy. ${ }^{7}$ These are similar to management programs for other types of cardiomyopathies which include the use of ACE inhibitors, beta blockers and aspirin therapy to relieve the pressure on the heart, implantation of pacemaker with implantable cardioverter defibrillator (ICD) is also an option for those thought to be at a high risk of malignant arrhythmia problems (ventricular tachycardia or fibrillation).

In severe cases NCC may lead to heart failure. Then heart transplant may be necessary.

\section{References:}

1. Maron, Barry.; Towbin, Jeffrey.; Thiene, Gaetano; Antzelevitch, Charles; Corrado, Domenico.; Arnett, D; Moss, AJ; Seidman, CE et al. Contemporary Definitions and Classification of the Cardiomyopathies. American Heart Association Journals (American Heart Association) 2006; 113 (14): 1807.
2. Vatta M, Mohapatra B, Jimenez S, et al. Mutations in Cypher/ ZASP in patients with dilated cardiomyopathy and left ventricular non-compaction. J. Am. Coll. Cardiol. 2003; 42 (11): 2014-27.

3. Espinola-Zavaleta, Nilda.; Soto, Elena.; Castellanos, Luis Munoz; Játiva-Chávez, Silvio; Keirns, Candace. Noncompacted Cardiomyopathy: Clinical-Echocardiographic Study. Cardiovasc Ultrasound 2006; 4 (1): 35. doi:10.1186/ 1476-7120-4-35.

4. Oechslin, Erwin; Jenni, Rolf . Non-compaction of the Left Ventricular Myocardium. Clinical Observation to the Discovery of a New Disease. 2007; 09: 29.

5. The Cardiomyopathy Association (2007-07-23). LV Noncompaction (website). http://www.cardiomyopathy.org/ index.php?id=274. Retrieved 2007-07-23.

6. Chin TK, Perloff JK, Williams RG, et al. Isolated noncompaction of left ventricular myocardium. A study of eight cases. Circulation 1990; 82(2):507-13.

7. Lorenzo Botto, MD (2004-September). "Left Ventricular Noncompacted” (PDF). http://www.orpha.net/data/patho/GB/ukLVNC.pdf. Retrieved 2007-06-13. 